\title{
Overexpression of 14-3-3 $\gamma$ Induces the Migration and Invasion of Human Lung Adenocarcinoma A549 Cells
}

\author{
Pritsana Raungrut, Ph.D. ${ }^{1}$, Nidanut Champoochana, B.Sc. ${ }^{1}$, Paramee Thongsuksai, M.D. ${ }^{2}$, \\ Kamontip Promnares, Ph.D. ${ }^{3}$
}

${ }^{1}$ Department of Biomedical Sciences and Biomedical Engineering, Faculty of Medicine, Prince of Songkla University, Hat Yai, Songkhla 90110, Thailand.

${ }^{2}$ Department of Pathology, Faculty of Medicine, Prince of Songkla University, Hat Yai, Songkhla 90110, Thailand. ${ }^{3}$ Department of Anesthesiology, University of Maryland School of Medicine, Baltimore 21201, The United States of America. Received 10 March 2020 • Revised 25 October 2020 • Accepted 25 October 2020 • Published online 1 April 2021

\begin{abstract}
:
Objective: 14-3-3 gamma $(\gamma)$ is known to modulate the development and progression of many cancers. However, the evidence in lung cancer is still unclear. In this study, effects of $14-3-3 \gamma$ on tumor cell migration and invasion were investigated.
\end{abstract}

Material and Methods: A 14-3-3y expression vector was made and transfected into A549 cells. In-vitro scratch assay and transwell assay were applied to assess migration and invasion, respectively. Western blotting was used to detect expression of proteins related to epithelial-mesenchymal transition.

Results: Closing rate of scratch wounds, both in classical and non-classical scratch assay, was significantly increased in 14-3-3 $\gamma$-overexpressing cells in comparison to the controls. Similarly, by transwell assay, a significant increase in the invasion and migration was shown in the 14-3-3 $\gamma$-overexpressing cells in comparison to the null vector cells, by approximately $79.2 \%$ ( $p$-value $=0.002$ ) and $131.2 \%$ ( $p$-value $<0.001)$, respectively. In addition, increased $14-3-3 \gamma$ expression resulted in a significant increase of $\beta$-catenin and Snail but not for E-cadherin and vimentin.

Conclusion: The study demonstrates the role of $14-3-3 \gamma$ protein on lung cancer progression via migration and invasion processes, possibly providing a new targeted therapy for non-small cell lung cancer.

Keywords: $14-3-3 \gamma$, A549 cells, epithelial-mesenchymal transition, invasion, migration

Contact: Pritsana Raungrut, Ph.D.

Department of Biomedical Sciences and Biomedical Engineering, Faculty of Medicine,

Prince of Songkla University, Hat Yai, Songkhla 90110, Thailand.

E-mail: rpritsan@medicine.psu.ac.th

This is an open access article under the CC BY-NC-ND license

(http://www.jhsmr.org/index.php/jhsmr/about/editorialPolicies\#openAccessPolicy).

J Health Sci Med Res 2021;39(5):401-409 doi: 10.31584 /jhsmr.2021796 www.jhsmr.org 


\section{Introduction}

Lung cancer is the most common malignant tumors, with an incidence (11.6\% of the total cases) and mortality rate $\left(18.4 \%\right.$ of the total cancer deaths). ${ }^{1}$ It is estimated that metastasis, wherein cancer cells spread throughout the body and establish new colonies in a distant organ, remains the cause of $90.1 \%$ of deaths. ${ }^{2}$ During tumor progression, acquisition of the migration and invasion abilities allows cancer cells to adjacent tissues and distant organ contributing to metastasis. ${ }^{3}$ Tumor metastasis is a process involving with several strategies, including switch in cell property from epithelial to mesenchymal phenotype or enhancing the ability of mesenchymal movement. ${ }^{4,5}$ Therefore, to control the metastasis, investigation of the key proteins regulating these processes is important for the development new therapeutic targets, so as to reduce mortality.

14-3-3 protein is a group of proteins consisting of seven distinct isoforms in human $(\beta, \gamma, \varepsilon, \eta, \sigma, \tau, \zeta){ }^{6}$ The 14-3-3 proteins directly bind to phosphor-serine/ threonine motifs of various protein partners. ${ }^{7}$ These proteins play crucial roles in the regulation of several biological processes; such as: apoptosis, cell signaling, protein trafficking, and cell adhesion and motility. ${ }^{8}$ Among 14-3-3 proteins, $14-3-3$ gamma $(\gamma)$ is one of the isoforms that relates to tumorigenesis. Increased expression of 14-3-3 $\gamma$ has been reported to be associated with poor survival and metastasis in breast ${ }^{9}$ and liver cancer. ${ }^{10}$ In lung cancer, our previous report has shown that 14-3-3y overexpression is related to nodal and distant metastasis in advanced nonsmall cell lung cancer (NSCLC) patients. ${ }^{11}$ In addition, we have also revealed that an decreased 14-3-3 $\gamma$ expression reduced invasion and migration abilities of NSCLC cells, by suppressing metalloproteinase enzyme through regulation of the epithelial-mesenchymal transition (EMT). ${ }^{12}$ In this study, we once again confirmed our previous results, by further exploration as to whether overexpression of 14-33y promotes the invasion and migration of A549 cells.

\section{Material and Methods Cell culture}

Human lung carcinoma cells (A549) were purchased from American Type Culture Collection [ATCC, Rockville, The United States of America (USA)]. Cells were cultured in Roswell Park Memorial Institute (RPMI)-1640 media (Invitrogen, Carlsbad, USA) supplementing with $10.0 \%$ fetal bovine serum albumin (FBS), and $1.0 \%$ penicillin/ streptomycin (Gibco, Grand Island, USA), then the cells were incubated in a humidified 5.0\% $\mathrm{CO}_{2}$ incubator at 37 ${ }^{\circ} \mathrm{C}$.

\section{Construction of recombinant deoxyribonucleic acid (DNA)}

Total ribonucleic acid (RNA) was extracted using Trizol reagent (Invitrogen). Complementary DNA (cDNA) was reverse-transcribed by Super Script pre-amplification kit (Bio-Rad Laboratories, Hercules, USA). A pair of specific primers, containing EcoRI and Xball restriction enzyme sites, were designed according the sequence of 14-3-

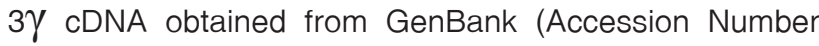
NM_012479). 14-3-3y cDNA was amplified by Polymerase Chain Reaction (PCR) using Thermal Cycler (Bio-Rad Laboratories). The amplified 14-3-3y cDNA was ligated into the pTracer-CMV2 mammalian expression vector (Thermo Fisher Scientific, Waltham, USA). Inserted 14-3-3y cDNA was confirmed by double restriction enzyme digestion at EcoRI and Xball sites (New England Biolabs, Ipswich, USA).

\section{Bacterial transformation}

Competent TOP10F' E. coli (Invitrogen) were prepared by the calcium chloride method. The recombinant

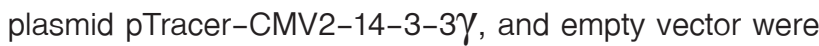
transformed to competent cells by heat-shock method. Transformant cells were streaked in Luria-Bertani (LB) agar, containing $100 \mu \mathrm{g} / \mathrm{ml}$ of ampicillin (Invitrogen, Carlsbad, USA) and incubated at $37^{\circ} \mathrm{C}$ for $16-20$ hours (hrs). Single colonies were randomly selected and cultured in LB broth 
containing $100 \mu \mathrm{g} / \mathrm{ml}$ of ampicillin at $37^{\circ} \mathrm{C}$ and agitated for 12 hrs. Plasmids were extracted and purified by S.N.A.P ${ }^{T M}$ plasmid DNA MiniPrep kit (Invitrogen). Positive plasmids were identified by DNA sequencing.

\section{Transient transfection}

A549 cells were suspended in antibiotic-free media containing $10.0 \%$ FBS and seeded into $24-$ well plates $\left(2 \times 10^{5}\right.$ cells/well) overnight. When the cells were approximately $80.0 \%$ confluent, they were then transfected with $20 \mu \mathrm{g}$ of

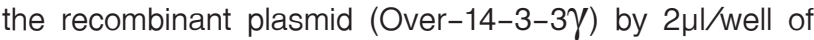
FUGENE $^{\circledast}$ HD transfection reagent (Promega, Madison, USA). The cells were then grown at $37^{\circ} \mathrm{C}$ in an atmosphere with $5.0 \% \mathrm{CO}_{2}$, for $48 \mathrm{hrs}$. The protein expression of $14-$ 3-3y of the transfected cells was determined by western blotting. Non-transfected cells (NT) and transfected cells with empty vector (Null vector) were assigned as the control.

3-(4,5-dimethylthiazol-2-yl)-2,5-diphenyltetrazolium bromide (MTT) assay

After cell transfection, the A549 cells were re-seeded into $96-$ well plates at a density of $0.5 \times 10^{5}$ cells/well. Then, the cells were cultured and treated with MTT solution as previously described. ${ }^{12}$ Mean absorbance value for the NT group was considered as $100 \%$ viability, while other groups were evaluated as a percentage of cell viability relative to the NT group.

\section{Western blotting}

Primary antibodies against $14-3-3 y$ (Santa Cruz Biotechnology, California, USA), E-cadherin, Vimentin, $\beta$-catenin, Snail, $\beta$-actin, and a horseradish peroxidaseconjugated, secondary antibody (Cell signaling technology, Danvers, USA) were used. Protein preparation and separation were performed as previously described. ${ }^{12}$ The membranes were probed with each primary antibody at a dilution of 1:500 overnight at room temperature, then further incubated with a secondary antibody (dilution of 1 : $2,000)$. Level of proteins was visualized using SuperSignal ${ }^{\mathrm{Tm}}$ West Dura extended duration chemiluminescent substrate (Thermo Fisher Scientific). Images were captured by a couple-charged device (CCD) camera (Vilber Lourmat, Eberhardzell, Germany). Band intensity was quantitated by Image J program version 1.51 (23 April 2018). Relative level of all proteins was calculated based on $\beta$-actin as an internal control.

\section{In vitro scratch assay}

Migration of tumor cells was investigated by scratch assay in a 96-well plate. The wells were pre-coated with $4.8 \mu \mathrm{g} /$ well of Matrigel ${ }^{\mathrm{Tm}}$ basement membrane matrix (BD Bioscience, Bedford, Massachusetts, USA) at $37^{\circ} \mathrm{C}$ for 30 minutes. Following transfection for $48 \mathrm{hrs}$, cells were harvested and re-suspended in $100 \mu \mathrm{l}$ of antibiotic-free media containing $10.0 \%$ FBS at a density of $0.8^{\prime} 10^{5}$ cells/ well. Then, the cells were incubated until the cells reached $90.0 \%$ confluence. A straight scratch was made by a pipette tip. Antibiotic-free media containing 1.0\% FBS was added and cultured for another $24 \mathrm{hrs}$. The same protocol was used for the classical scratch assay, except that the wells were not pre-coated with the Matrigel. Ability of cell migration was photographed at 0,6 , and 24 hrs using an inverted microscope equipped with a digital camera (Olympus, Tokyo, Japan). Width of wound field was measured as well as which percentage of wound closer was calculated by the following formula:

$$
\% \text { of wound closer }=\left[\frac{W_{t=0 h}-W_{t=\Delta h}}{W_{t=0 h}}\right] \times 100
$$

Wherein, $W_{t=0 h}$ was the width of wound field immediately after scratching, and $\mathrm{W}_{\mathrm{t}=\Delta \mathrm{h}}$ was the width of wound field measured at 6 or $24 \mathrm{hrs}$ 


\section{Transwell migration and invasion assay}

Abilities of cell migration and invasion were determined using a transwell insert attaching with 8.0- $\mu \mathrm{m}$ pore membranes (Corning Inc., Corning, New York, USA) according to our previous study. ${ }^{12}$ A549 cells at a density of $0.5 \times 10^{5}$ cells were suspended in an antibiotic-free media containing 1.0\% FBS $(200 \mu \mathrm{l})$ and loaded into the insert, upon which $500 \mu \mathrm{l}$ of antibiotic-free media containing $10.0 \%$ FBS as a chemoattractant was added to the lower chamber. After $48 \mathrm{hrs}$, the cells that migrated and invaded into the lower membrane surface were stained with crystal violet solution. The number of stained cells was counted from 10 random fields of each insert.

\section{Statistical analysis}

Mean ( \pm standard deviation, S.D.) was calculated from three independent experiments, each performed in triplicate. Differences between experiment groups were tested by unpaired t-test using GraphPad Prism software (GraphPad Prism, San Diego, California, USA). P-values $<0.050$ was considered as statistical significance.

(A)

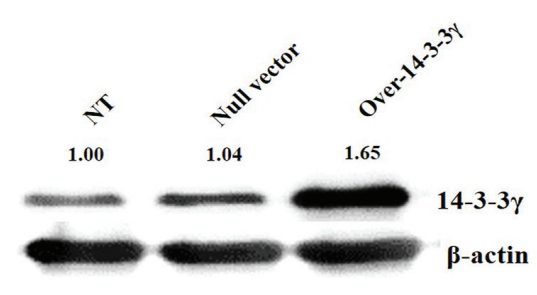

\section{Results}

After transient transfection, the results revealed an increase of $14-3-3 \gamma$ expression by $65.3 \%$ and $61.1 \%$ in transfected cells, compared to NT and Null vector groups, respectively (Figure 1A, all p-value<0.001). Subsequently, the cell viability of the A549 cells was measured by the MTT assay and there was no effect on viability in 14-3-3 $\gamma$-overexpressing cells (Figure 1B).

\section{Effect of $14-3-3 \gamma$ on wound healing of A549} cells

Analysis of the motility behavior of A549 cells showed that: in classical scratch assay, 14-3-3y-overexpressing cells exhibited significant increase of migration ability by $33.3 \%$ ( $p$-value $<0.001), 36.4 \%$ ( $p$-value $<0.001$ ) at $6 \mathrm{hrs}$, $29.2 \%(p-$ value $=0.009)$ and $18.6 \%(p-$ value $=0.015)$ at 24 hrs, compared to the NT and Null vector groups, respectively (Figure 2A).

In addition, to the given normal physiological condition of cell migration, the non-classical scratch assay, in which plates were pre-coated with Matrigel $^{\mathrm{TM}}$, was also
(B)

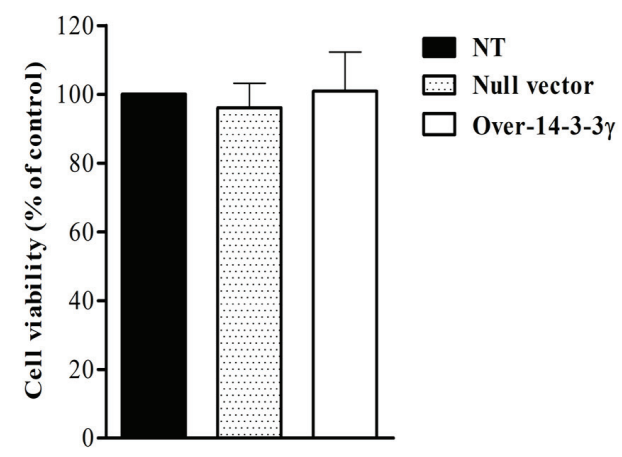

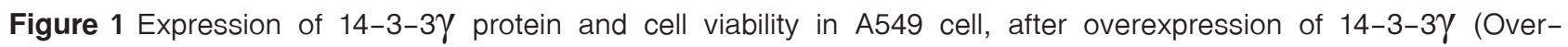

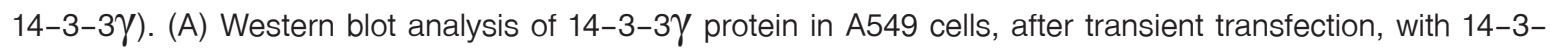
3 $\gamma$ plasmid. $\beta$-actin served as a loading control. (B) Effect of overexpression of $14-3-3 \gamma$ on cell viability determined by the MTT assay. Data are expressed as the mean \pm standard deviation from three, independent experiments. Non-transfected cells (NT), Empty vector-transfected cells (Null vector). 
(A)
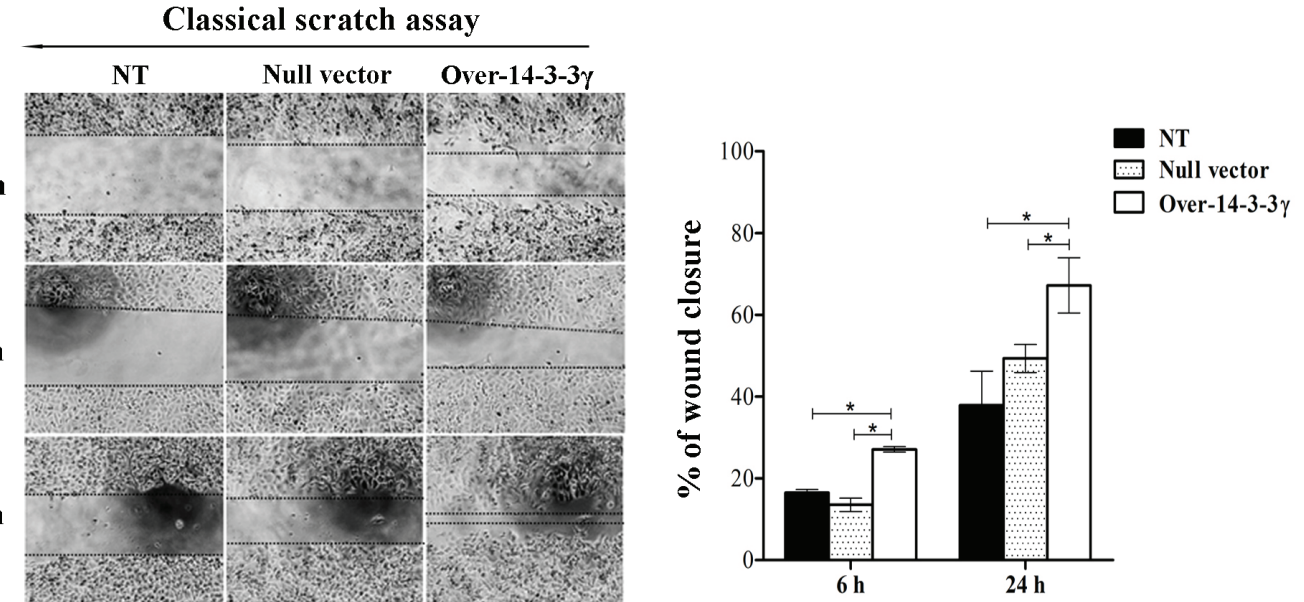

(B)

Non-classical scratch assay
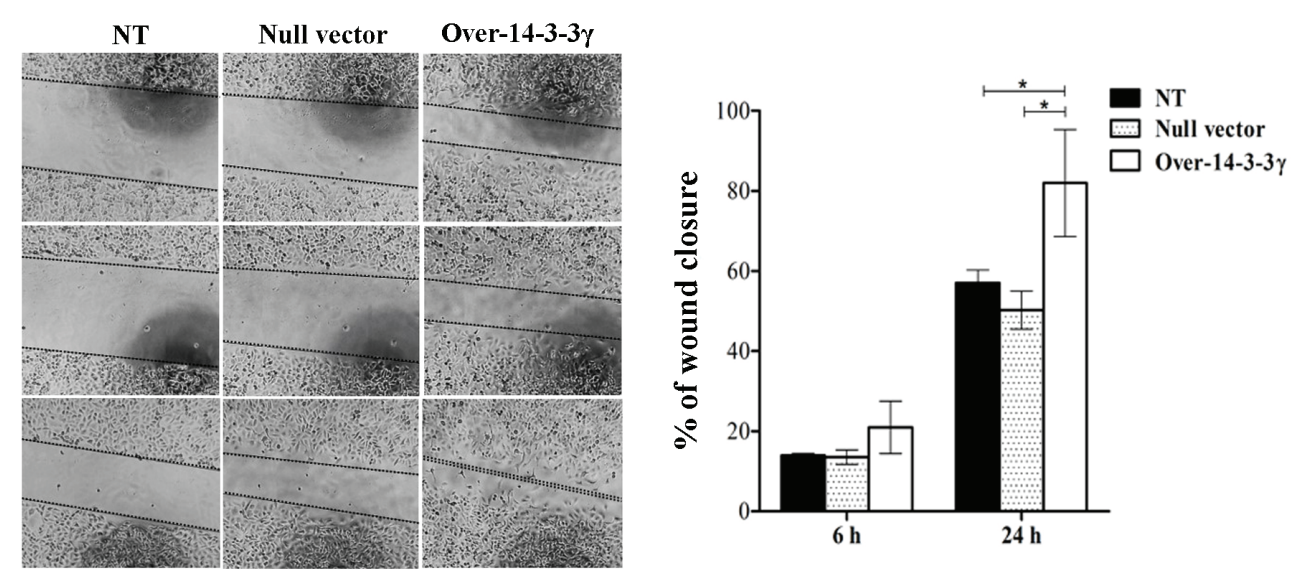

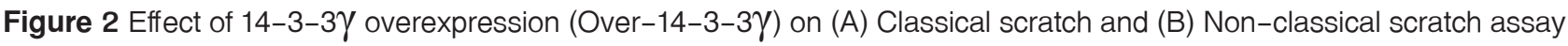
of A549 cells at 6 and 24 hour. Straight scratch was photographed under microscope. Original magnification, 20x. Data are expressed as the mean \pm standard deviation from three-independent experiments.

*Significantly different from non-transfected cells (NT), or empty vector-transfected cells (Null vector) at $p$-value< 0.050 .

performed. The result showed that the migration ability was obviously increased after overexpression of 14-3-3y by $25.5 \%$ ( $p$-value $=0.048$ ) and $32.1 \%$ ( $p$-value=0.002), in comparison to the NT and Null vector groups, respectively at $24 \mathrm{hrs}$ (Figure 2B).
Effect of $14-3-3 \gamma$ on transwell migration and invasion abilities of A549 cells

Ability of invasion coupled with migration after 143-3 $\gamma$ transfection was determined by transwell assay. The results revealed that: 14-3-3 $\gamma$ displayed significant 
increase in both invasion of A549 cells $(79.5 \%$ increase in comparison to the Null vector group, $\mathrm{p}$-value=0.002) in addition to migration $(131.0 \%$ increase in comparison to the

Null vector group, p-value<0.001) (Figure 3).
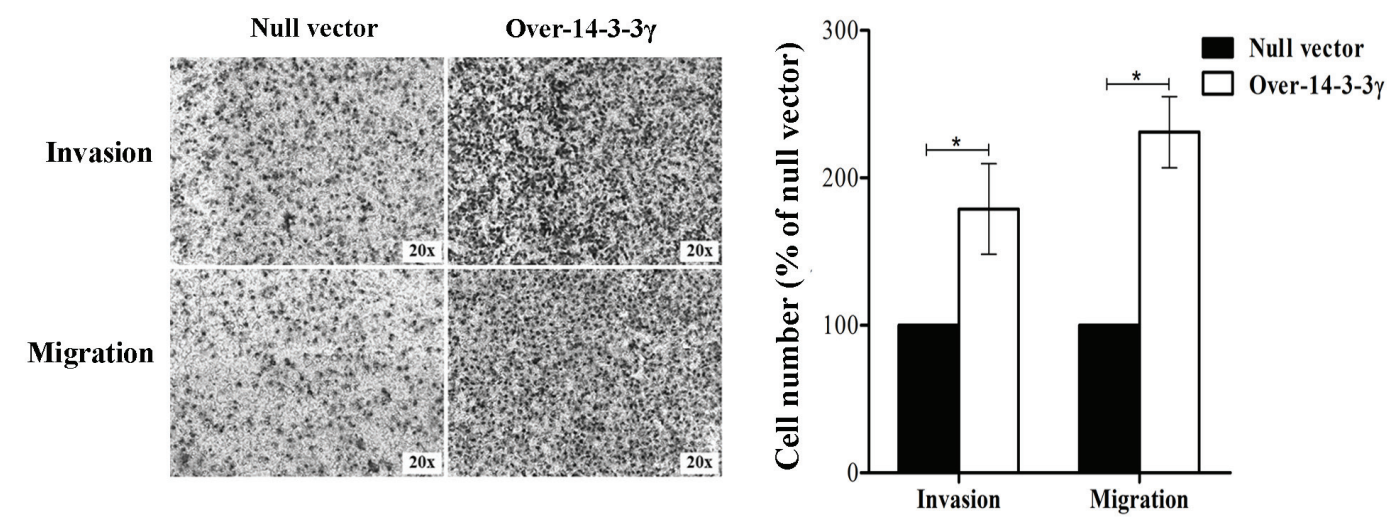

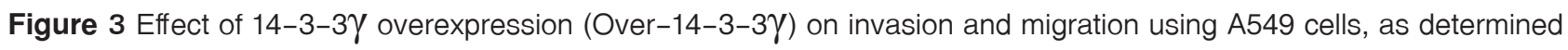
by transwell assay. The invading and migrating cells on the lower surface of the membranes were stained with crystal violet. Original magnification, 20x. The number of cells was determined under amicroscope. Data are expressed as the mean \pm standard deviation from three, independent experiments.

*Significantly different from empty vector-transfected cells (Null vector) at $p$-value $<0.050$.
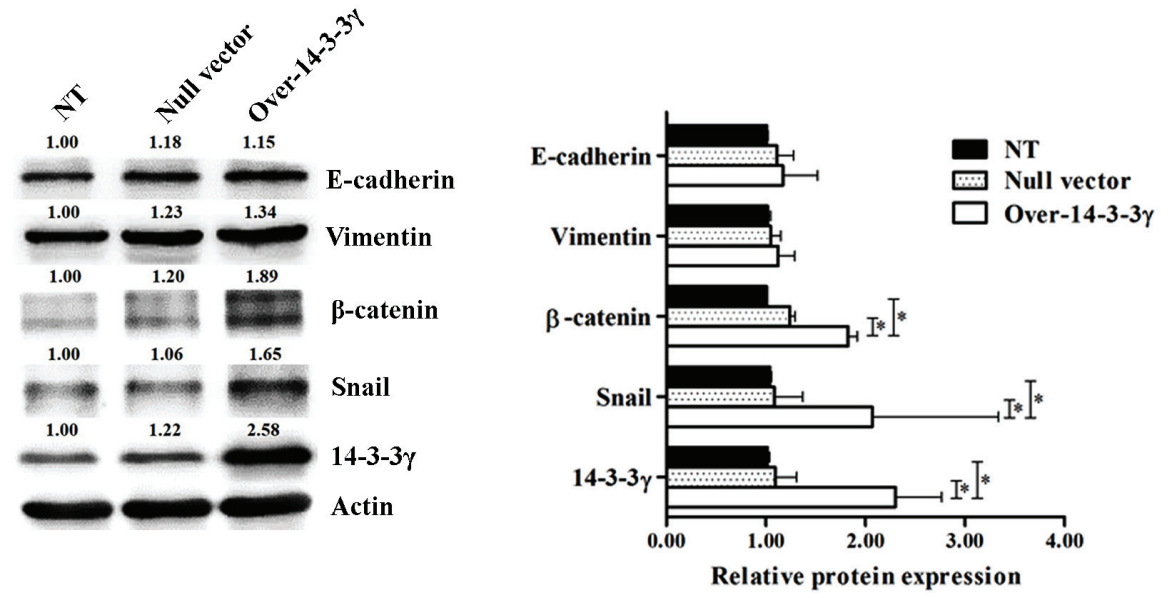

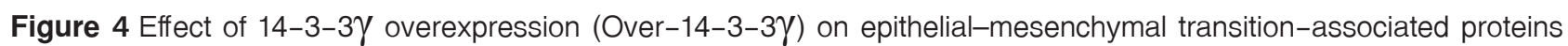
in A549 cells, as demonstrated by western blot analysis. $\beta$-Actin was used as a loading control. Data are expressed as the mean \pm standard deviation from three, independent experiments.

*Significantly different from non-transfected cells (NT), or empty vector-transfected cells (Null vector) at p-value $<0.050$. 
Effect of 14-3-3 $\gamma$ on the expression of EMTassociated proteins in A549 cells

To further understand the molecular mechanism that regulates the cell phenotype, we evaluated the change of EMT-related proteins after overexpression of $14-3-3 \gamma$ by western blotting. We found no significant alteration of expression level of E-cadherin and vimentin. However, a significant increase of $\beta$-catenin was found in 14-3-3 $\gamma$-overexpressing cells at $81.2 \%(p-$ value $=0.007)$ and $47.7 \%$ ( $p$-value=0.017), in comparison to the NT and Null vector groups, respectively. Similarly, an elevated expression of 14-3-3 $\gamma$ in A549 cells remarkably increased Snail expression by $44.3 \%$ ( $p$-value $=0.025$ ) and $52.6 \%$ ( $p$-value $=0.033$ ), in comparison to NT and Null vector groups, respectively (Figure 4).

\section{Discussion}

In the present study, we demonstrated that overexpression of 14-3-3 $\gamma$ significantly promoted the invasion as well as migration of A549 cells, by enhancing the EMT-associated proteins; such as, $\beta$-catenin and Snail, but not E-cadherin and vimentin. It has been revealed that the enhanced expression of $14-3-3 \gamma$ is significantly associated with tumorigenesis of various cancers. For example, 14$3-3 \gamma$ is reported to be differentially expressed in head and neck squamous cell carcinoma ${ }^{13}$ and osteosarcoma. ${ }^{14}$ A study of Ajjappala et al. revealed that: IL-3 induces expression of $14-3-3 \gamma$, with eventually activates the phosphoinositide 3-kinase (PI3K) and mitogen-activated protein kinase (MAPK), which in turn signals pathways to promote survival and growth of hematopoietic $\mathrm{Ba} / \mathrm{F} 3$ cells. ${ }^{15}$ Similarly in NIH3T3 mouse fibroblast cells, ectopic expression of 14-3-3y initiates tumor formation in SCID mice, via the activation of PI3K and MAPK pathways. ${ }^{16}$ Furthermore, increased expression of $14-3-3 \gamma$ is shown in hepatocellular carcinoma ${ }^{10,17}$ and breast cancer ${ }^{9}$, with a significant association of worse progression-free and overall survival. ${ }^{9,10}$
For lung cancer, several studies have revealed that: the 14-3-3y is involved with tumorigenesis. Qi et al. (2005) have shown that: 14-3-3 $\gamma$ is one of 14-3-3 isoforms existing only in tumor tissues and NSCLC cell lines (A549 and $\mathrm{H} 358$, except in $\mathrm{H} 322$ ), with high abundance. ${ }^{18}$ Ectopic expression of $14-3-3 \gamma$ in H322 cells causes polyploidy promoting cell cycle progression. ${ }^{19,20}$ We previously found that 14-3-3y overexpression in tumor is related to nodal and distant metastasis in advanced NSCLC. ${ }^{11}$ In the current study, we confirmed these results in that: 14-3-3y overexpression significantly enhanced the ability of cell migration and invasion of lung cancer, indicating in the oncogenic role of 14-3-3 $\gamma$.

Cell migration and invasion are key steps leading to the metastasis of tumors. More recently, Hiraoka et al. have shown that pseudopodial protrusion, which is an associated process with tumor cell migration and invasion, are induced in 14-3-3 $\gamma$-overexpressing breast cancer cells. $^{21}$ In our previous study, we had shown a significant reduction of invasion and migration in 14-3-3 $\gamma$-suppressing A549 and H358 cells, which is involved with inhibition of matrix metalloproteinase (MMP)-2 and MMP-9, through the regulation of EMT. ${ }^{12}$ Over the past several decades, there has been a dramatic increase in the studies showing the association of 14-3-3 protein with EMT-related proteins. By sequence scanning, Hou et al. revealed that Snail, a prominent inducer of EMT by repressing E-cadherin expression, binds directly to $14-3-3$ proteins and this interaction significantly induces Snail-mediated repression and EMT. ${ }^{22}$ Accordingly, synergistic effect of $14-3-3 \zeta$, and atypical protein kinase $C$ leads to Snail expression during the EMT of $\mathrm{A} 549$ cells, via the NF-KB pathway ${ }^{23}$ and cholangiocarcinoma cells via the GSK-3 $\beta$ pathway. ${ }^{24}$ Furthermore, phosphorylation of $\beta$-catenin, resulting in the $\beta$-catenin/14-3-3 ל complex formation, promotes cell invasiveness through activation of EMT. ${ }^{25} \mathrm{~A}$ study by Lai et al. (2014) also demonstrated that $14-3-3 \gamma$ binds directly to $\beta$-catenin. ${ }^{26}$ Since $14-3-3$ proteins function through 
binding to various proteins ${ }^{8,27}$, an increase in $\beta$-catenin and Snail because of, an increased expression of 14-3-3y contributes to induction of metastatic phenotype of A549 cells in our study.

Although, substantial alteration of the migration and invasion abilities and EMT-associated proteins was observed, transient expression of 14-3-3 $\gamma$ did not alter the EMT markers, E-cadherin and vimentin in the present study. This result is in contrast to our previous report showing that knockdown of $14-3-3 \gamma$ contributed to reduction of the expression of vimentin in A549 and H358 cells. ${ }^{12}$ It may due to the fact that $14-3-3 \gamma$ expression level might be not enough to affect the EMT markers. In addition, there is evidence showing that the status of epithelial and mesenchymal markers is not always an indicator for EMT. Hollestelle et al. have found that not all human breast cancer cell lines that have undergone EMT have concomitantly lost E-cadherin, and gained $\mathrm{N}$-cadherin and vimentin. ${ }^{28}$ This may indicate that, in our study, a significant alteration of E-cadherin and vimentin is not a necessity for the EMT and other regulating pathways may be involved.

\section{Conclusion}

The results of our study indicate that 14-3-3y could promote migration and invasion in A549 human lung carcinoma cells. Therefore, 14-3-3 $\gamma$ may be a promising anti-metastasis candidate gene for NSCLC.

\section{Acknowledgement}

This study was funded by Faculty of Medicine, Prince of Songkla University, Songkhla, Thailand (grant no. 570230042). The Research center for cancer control in Thailand are acknowledged for their research facilities.

\section{Conflict of interest}

The authors declare that they have no competing interests.

\section{References}

1. Bray F, Ferlay J, Soerjomataram I, Siegel RL, Torre LA, Jemal A. Global cancer statistics 2018: GLOBOCAN estimates of incidence and mortality worldwide for 36 cancers in 185 countries. CA Cancer J Clin 2018;68:394-424.

2. Seyfried TN, Huysentruyt LC. On the origin of cancer metastasis. Crit Rev Oncog 2013;18:43-73.

3. Hanahan D, Weinberg RA. The hallmarks of cancer. Cell 2000;100:57-70.

4. Son $\mathrm{H}$, Moon A. Epithelial-mesenchymal Transition and Cell Invasion. Toxicol Res 2010;26:245-52.

5. Friedl $P$, Wolf $K$. Tumour-cell invasion and migration: diversity and escape mechanisms. Nat Rev Cancer 2003;3:362-74.

6. Aitken A. 14-3-3 proteins: a historic overview. Semin Cancer Biol 2006;16:162-72.

7. Yaffe MB. How do 14-3-3 proteins work?-- Gatekeeper phosphorylation and the molecular anvil hypothesis. FEBS Lett 2002;513:53-7.

8. Fu H, Subramanian RR, Masters SC. 14-3-3 proteins: structure, function, and regulation. Annu Rev Pharmacol Toxicol 2000; 40:617-47.

9. Song $Y$, Yang Z, Ke Z, Yao Y, Hu X, Sun Y, et al. Expression of 14-3-3gamma in patients with breast cancer: correlation with clinicopathological features and prognosis. Cancer Epidemiol 2012;36:533-36.

10. Ko BS, Lai IR, Chang TC, Liu TA, Chen SC, Wang J, et al. Involvement of 14-3-3gamma overexpression in extrahepatic metastasis of hepatocellular carcinoma. Hum Pathol 2011;42: 129-35.

11. Raungrut $\mathrm{P}$, Wongkotsila A, Lirdprapamongkol K, Svasti J, Geater SL, Phukaoloun M, et al. Prognostic significance of 14-3-3gamma overexpression in advanced non-small cell lung cancer. Asian Pac J Cancer Prev 2014;15:3513-8.

12. Raungrut $\mathrm{P}$, Wongkotsila $\mathrm{A}$, Champoochana $\mathrm{N}$, Lirdprapamongkol K, Svasti J, Thongsuksai P. Knockdown of 14-3-3gamma Suppresses Epithelial-Mesenchymal Transition and Reduces Metastatic Potential of Human Non-small Cell Lung Cancer Cells. Anticancer Res 2018;38:3507-14.

13. Wang B, Wang T, Cao XL, Li Y. Critical genes in head and neck squamous cell carcinoma revealed by bioinformatic analysis of gene expression data. Genet Mol Res 2015;14: 17406-15. 
14. Wang $\mathrm{YB}$, Jia $\mathrm{N}$, Xu CM, Zhao L, Zhao $\mathrm{Y}$, Wang $\mathrm{X}$, et al. Selecting key genes associated with osteosarcoma based on a differential expression network. Genet Mol Res 2015;14: 17708-17

15. Ajjappala BS, Kim YS, Kim MS, Lee MY, Lee KY, Ki HY, et al. 14-3-3gamma is stimulated by IL-3 and promotes cel proliferation. J Immunol 2009;182:1050-60.

16. Radhakrishnan VM, Martinez JD. 14-3-3gamma induces oncogenic transformation by stimulating MAP kinase and PI3K signaling. PLoS One 2010;5:e11433.

17. Lee IN, Chen CH, Sheu JC, Lee HS, Huang GT, Yu CY, et al. Identification of human hepatocellular carcinoma-related biomarkers by two-dimensional difference gel electrophoresis and mass spectrometry. J Proteome Res 2005;4:2062-9.

18. Qi W, Liu X, Qiao D, Martinez JD. Isoform-specific expression of 14-3-3 proteins in human lung cancer tissues. Int $\mathrm{J}$ Cancer 2005;113:359-63

19. Qi W, Liu X, Chen W, Li Q, Martinez JD. Overexpression of 14-3-3gamma causes polyploidization in H322 lung cancer cells. Mol Carcinog 2007;46:847-56.

20. Gomes CJ, Centuori SM, Harman MW, Putnam CW, Wolgemuth CW, Martinez JD. The induction of endoreduplication and polyploidy by elevated expression of 14-3-3gamma. Genes Cancer 2017;8:771-83.

21. Hiraoka E, Mimae $T$, Ito M, Kadoya $T$, Miyata $Y$, Ito A, et al. Breast cancer cell motility is promoted by 14-3-3gamma. Breast Cancer 2019;26:581-93.
22. Hou Z, Peng $H$, White DE, Wang $P$, Lieberman $P M$, Halazonetis T, et al. 14-3-3 binding sites in the snail protein are essential for snail-mediated transcriptional repression and epithelial-mesenchymal differentiation. Cancer Res 2010;70: 4385-93

23. Tong S, Xia T, Fan K, Jiang K, Zhai W, Li JS, et al. 14-3-3zeta promotes lung cancer cell invasion by increasing the Snail protein expression through atypical protein kinase C (aPKC)/NF-kappaB signaling. Exp Cell Res 2016;348:1-9.

24. Yang $Y$, Liu $Y$, He JC, Wang JM, Schemmer $P$, Ma CQ, et al. 14-3-3zeta and aPKC-iota synergistically facilitate epithelialmesenchymal transition of cholangiocarcinoma via GSK-3beta/ Snail signaling pathway. Oncotarget 2016;7:55191-210.

25. Chen $\mathrm{CH}$, Chuang SM, Yang MF, Liao JW, Yu SL, Chen JJ. A novel function of YWHAZ/beta-catenin axis in promoting epithelial-mesenchymal transition and lung cancer metastasis. Mol Cancer Res 2012;10:1319-31.

26. Lai XJ, Ye SQ, Zheng L, Li L, Liu QR, Yu SB, et al. Selective 14-3-3gamma induction quenches p-beta-catenin Ser37/ Bax-enhanced cell death in cerebral cortical neurons during ischemia. Cell Death Dis 2014;5:e1184.

27. Hermeking $\mathrm{H}$. The 14-3-3 cancer connection. Nat Rev Cancer 2003;3:931-43.

28. Hollestelle A, Peeters JK, Smid M, Timmermans M, Verhoog LC, Westenend PJ, et al. Loss of E-cadherin is not a necessity for epithelial to mesenchymal transition in human breast cancer. Breast Cancer Res Treat 2013;138:47-57. 